\title{
Fostering Intercultural Communication Competence of University Foreign Affairs Administrators
}

\author{
Jiajun Shen \\ College of Civil Engineering \\ Tongji University \\ Shanghai, China \\ shenjiajun@tongji.edu.cn
}

\author{
Hongwei Huang \\ Department of Geotechnical Engineering College of Civil \\ Engineering \\ Tongji University \\ Shanghai, China \\ huanghw@tongji.edu.cn
}

\begin{abstract}
With the globalization of higher education, the exchange and cooperation between universities is greatly increased. Foreign Affairs administrators in Universities bridge all kinds of international cooperation. They are the window to the outside world and could play a crucial role for the success of cooperation. The intercultural communication is a necessity in their work. In this paper, the authors discuss several issues relating intercultural communication, intercultural communication competence and finally give some strategies about fostering intercultural communication competence of foreign affairs administrators.
\end{abstract}

Keywords-Intercultural communication competence; Foreign affairs administrators University

\section{INTRODUCTION}

In recent years, scholars from China began to realize that language skills (including skills of listening, speaking, reading, writing, and translating) do not necessarily lead Chinese English learners to a successful communication with the culturally different others because effective intercultural communication requires more than foreign language skills.

In order to communicate successfully with the culturally different others, communication participants need to have appropriate intercultural communication competence (ICC). Some scholars have been discussing issues relating to the development of college students' intercultural communication competence in their English-learning process, but up to now few research has been conducted in Chinese cultural context on how English learners can develop their ICC.

At the age of global village, intercultural communication competence has become an indispensable ability for foreign affairs administrators because they have more chance to communicate with the culturally different others than those who do not work in this field, but what should be done to improve their intercultural communication competence? This is a question that is rarely studied by intercultural communication scholars in China or elsewhere.

\section{THE IMPORTANCE OF Foreign AfFAIRS IN UNIVERSITIES}

With the development of world economy, the internation-al exchange and cooperation in different levels has been greatly increased in our universities. More and more foreign students come to study in China, and there is also an increasing number of foreign teachers. Meanwhile, the number of international cooperation programs keep increasing in our universities and more students and teachers join all kinds of international exchange.

The globalization of higher education has been a trend. Foreign affairs administrators act as a bridge between the university and the outside world. Some new characteristics appear in the process of globalization: besides cooperating with universities in developed countries, our universities began to have some cooperation with universities in developing countries in Asia and Africa. It is a great challenge for foreign affairs administrators to communicate successfully and effectively with counterparts from different culture. It is their responsibility to introduce the development of teaching, scientific research and other strong points of our universities to the foreign universities and introduce high level talents, advanced teaching techniques and management methods to our universities. It is of great importance to build a grand platform for international cooperation and exchange. During the building of the platform, it's inevitable to communicate with counterparts of different languages and cultures. Intercultural communication become a necessity for foreign affairs administrators and fostering their intercultural communication competence is crucial for the effective communication.

\section{INTRODUCTION TO INTERCULTURAL COMMUNICATION}

The field of intercultural communication emerged during the Cold War era of the 1950s, 1960s, and 1970s and its practical beginnings or techniques were developed earlier in the twentieth century around the study of linguistics and anthropology. Intercultural communication can be more precisely defined as the heterophilous communication exchange between multiple cultures. Although there is some debate over the precise origins of intercultural communication 
most communication scholars recognize E.T. Hall as the implicit founder of the field of study.

Intercultural communication means the communication between different cultures. It needs to deal with the relationship between communication and culture and the problems in the cross-cultural context. Intercultural communication is a universal phenomenon. When you talk with an Australian student, or send an email to a foreign teacher, or even when you watch a foreign film, listen to some Russian music or read an English novel, you are involved in intercultural communication. The commu-nication between cultures today is happening continuously at all times. One of its characteristics is that with different backgrounds, the communicator's language, history, living environment, customs, communication rules, thinking patterns and values would be different to varying degrees. People are accustomed to their own cultures. They would find that something they like or something they think is normal in their own culture would be disliked or would be thought inappropriate for people from different cultures. Something which they think is not very good would be appreciated by people from different cultures. The intercultural communication is inevitably for university foreign affairs administrators in their daily work.

\section{INTERCULTURAL COMMUNICATION COMPETENCE}

The notion of intercultural communication competence was made popular by Byram and his colleagues. Intercu-ltural communication competence (IC) is defined as the ability to act within a given context in a responsible and adequate way and as the 'readiness to suspend disbelief and judgment with respect to others' meanings, beliefs and behaviours' and a 'willingness to suspend belief in one's own meanings and behaviours, and to analyse them from the viewpoint of the others with whom one is engaging'.

Byram's intercultural communicative competence(ICC) model presents a conceptual framework consisting of fourinterrelated components: knowledge, skills, attitudes and awareness. Within this framework, cultural learning goes beyond a superficial "facts only" approach in learning a language. To become competent intercultural speakers, learners need to be open-minded to people of other cultures so that they understand cross-cultural perspectives with non-judgmental attitudes and respect. In developing ICC, learners are encouraged to reflect upon the cultural similarities and differences, and further develop the intercultural competence so as to be able to deal with situations where different cultures meet. Intercultural communication competence involves the interrelation between knowledge, skills and action in the acquisition of the ability to communicate professional expertise. Competence development is triggered when learners identify and acquire new information. They reflect on this new information and connect it to their existing body of knowledge, which is rooted in a mental network of meaning. This reflection process results in new knowledge. The integration of this new knowledge leads to new capabilities in their professional domains Units.
Interculturally competent persons know how to lead to a desired response in interactions, and to achieve their own communication goals by respecting and affirming the others' cultural conventions, values, mode of thinking, worldview and cultural identities. In other words, intercultural communication competence is the ability to acknowledge, respect, tolerate, and integrate cultural differences that exist between individuals, social members, ethnic groups, and countries, etc. Fostering the high tolerance of various cultural differences, and learning to deal with the cultural differences through mutual coordination, is the core of developing intercultural communication competence.

The fact is many foreign affairs administrators, although knowing a lot about the target language, were unable to communicate appropriately and effectively in it. Therefore, it is urgent to improve foreign affairs administrators' intercultural communication competence.

\section{THE IMPORTANCE OF INTERCULTURAL COMMUNICATION COMPETENCE TRAINING}

Intercultural awareness cannot grow naturally. It has to be trained and acquired. In native language learning, a child's acquisition of the linguistic competence (learning the language forms) goes hand in hand with the acquisition of "culture competence", which mutually support one another. People, who have been thus initiated into the culture in association with their native language, are naturally apt to interpret things with their own cultural preferences. This natural inclination is called "intuitive competence". When people from different cultural background communicate, their respective "intuitive competence" may cause cultural misunderstanding. "Intuitive competence" is something that native speakers possess, but foreign learners have to be trained. Therefore, it becomes necessary to foster foreign affairs administrators' intercultural competence.

\section{STRATEGIES TO FOSTER INTERCULTURAL COMMUNICATION COMPETENCE}

Foreign Affairs play a crucial role in the globalization of higher education. Foreign affairs administrators need to communicate with overseas students, foreign scholars, visitors and teachers in their daily work. How to foster intercultural communication competence of foreign affairs administrators has become a problem that demands our serious concern and prompt solution. We can embark on the problem from the following aspects.

\section{A. Learning about Foreign Language}

English is a global language and it is also the most commonly used language of the foreign affairs administrators. Many foreigners from non-English Speaking countries could speak English. Fluent and idiomatic oral and written English is the first step for effective communication. With the expansion of cooperation with non-English speaking countries, many universities employ non-English foreign language speaker to coordinate programs in those non-English speaking regions. It is necessary to keep learning foreign languages by reading 
books( newspapers and magazines), watching some TV programs and so on. To better grasp the language, it is also important to know the history, geography, culture and humanities of the foreign countries.

\section{B. Obtaining Cultural Knowledge}

Cultural Knowledge refers to the cognitive information you need to have about the people, the context, and the norms of appropriateness that run in a specific culture. Without such knowledge, it is likely that you will not interpret correctly the meanings of other people's messages, nor will you be able to choose behaviors that are appropriate and that allow you to achieve your objectives. Knowledge here refers to both culturegeneral and culture-specific knowledge. The former refers to the theories or themes that are commonly encountered in intercultural interactions regardless of the cultures involved. It furnishes insight into the intercultural communication process and can therefore be a very powerful tool in making sense of cultural practices. The latter refers to customs, etiquettes, and rules that are specific to the various cultures. Such information is used to understand a particular culture.

To foreigners, foreign affairs administrators might stand for a university. Whether they know the etiquettes of different occasions and events and arrange the details appropriately might impact the results of cooperation or even the image of the whole university. The foreign affairs administrators should learn the etiquettes of meetings, tables, car seats and so on. During communication, it is also important to understand and respect the religions and customs of the foreigners. To obtain cultural knowledge, they need to read extensively to learn the target language country's economic situations, political structure, social life, history and geography, science and technology, local traditions and conventions, literature and religion.

\section{Mastering Communication Skills}

Communication is crucial in foreign affairs. It is the basic for mutual understanding. Skills refer to how well the behaviors that are regarded as appropriate and effective are actually performed. Understanding the theories and concepts in intercultural communication does not necessarily lead to culturally sensitive behaviors. People who are knowledgeable about intercultural issues are not necessarily competent communicators until they have practiced the appropriate skills. Skills can also be divided into culture-general and culturespecific skills. Culture-general skills, such as the ability to tolerate ambiguity, manage stress, establish realistic expectations, and demonstrate flexibility and empathy are helpful tools in all types of intercultural adjustment. Culturespecific skills cover a large area, which can be trained and developed through everyday lives and business practices.

\section{Increasing Intercultural Awareness}

Globalization demands the enhancement of intercultural communication among people from diverse cultures. As a component of intercultural communication competence, intercultural awareness is an indispensable element for us to reach this global mindset. Sue et al identified 4 awareness competencies.

1) Self-awareness. It requires people to become aware of the way their own lives have been shaped by the culture into which they were born. This is also be accompanied by learning to respect and become sensitive to culturally different others.

2) Consciousness of One's Values and Biases and Their Effects. It requires conscious awareness of one's own values and biases and how they affect the way one interacts with culturally different people.

3) Necessity of Becoming Comfortable with Differences. People should not be afraid of recognizing and admitting there are differences. They should feel comfortable with the awareness that they may not be able to behave according to these other values.

4) Sensitivity to Circumstances. Being sensitive to circumstances implies that human beings are not always reliable and that there may be certain cultural groups in which some people have a very hard time interacting.

\section{E. Paying attention to the non-language communication competence training}

The fostering of non-language communication competence should not be neglected. The reasons for many misunderstandings and conflicts during communication are not language itself, but only because a glance, hand shaking or some other small gestures. For human communication, a part of the message is conveyed by languages, and a part of the message is conveyed by non-language communication. Different cultures have different non-language communication behavior. For example, in China, when you give others the thumbs up, you are showing your praise, but in some other cultures, it means something negative. It is necessary to pay attention to the non-language communication competence training in daily life.

\section{F. Being a good observer and seeking advices}

To communicate successfully with people from different cultural backgrounds demands that foreign affairs administrators must be good at observation and listen to advice with an open mind. Although there are many ways of observation, whichever way they may use, they must objectively observe the differences and similarities between different cultures, thereby finding out people's differences in social attitudes and social behaviors. But only being good at observation is not sufficient. If they meet with some cultural problems, and they can not understand them by their own knowledge, they have to seek advice with an open mind from other people, thereby eliminating misunderstanding during communication.

\section{CONCLUSIONS}

With the globalization of higher education, the universities in the world are getting closer to each other. The foreign affairs administrators play an important role in facilitating the cooperation and exchange between universities. They need to communicate with students and teachers from different cultures all over the world. It is important to foster their 
intercommunication competence to achieve success and efficient communication. There are 6 ways to foster their intercommunication competence: to have a good grasp of foreign language, to obtain cultural knowledge, to master communication skills, to increase intercultural awareness, to pay attention to the non-language communication competence training and to be a good observer and seeking advices from others. Each of these components alone is not sufficient to achieve intercultural communication competence.

Successful intercultural communication requires much enthusiasm and a willingness to overcome cultural barriers. It is a two-way process. The ways different cultures approach communication is one of the most important things to take into consideration when planning a collaborative effort that bridges multiple cultures. This cross-cultural collaboration is becoming more widespread as the dawn of the Internet Age brings the world closer and closer.

\section{REFERENCES}

[1] Ge, Z. X., \& Shi, M. L. "Intercultural communication and foreign langua ge teaching.” Journal of Zhengzhou University, 2001, 34(5), pp.46-49.

[2] Hu, W. Q. "How to train students to communicate with foreigners in for eign language teaching." Journal of Xinjiang Vocational University, 13( 2), pp. 63-64.

[3] Liu, H. "Intercultural communication and foreign language teaching." Journal of Hunan University (Social Science Edition), 2001, 15(2), pp. 187-189.

[4] Xue, J. P., \& Wang, R. H. "A probe into some problems of crosscultural communication in foreign language teaching." Research on education Tsinghua University, 2002,4, pp.71-76.

[5] Gao,Y. H, "Foreign language teaching and intercultural communication." Journal of Sichuan International Studies University,2001, 17(2), pp. 101-102.

[6] Zhang, H. M. (2004). "Foreign language teaching and the developmentof intercultural communication awareness."Journal of Shandong Teachers Normal University, 2004,1(18), pp.2-25.

[7] Peng, S. Y. "Intercultural communication research in China: Status quo, problems, and suggestions." Journal of HunanUniversity (Social Science Edition), 2005, 19(4), pp. 86-91.

[8] Rogers, E. M., \& Hart, W. B. "The histories of intercultural, international, and developmental communication." In W. B. Gudykunst, \& B. Mody (Eds.), Handbook of international and intercultural communication. 2001, (1), pp. 1-18.

[9] Leeds-Hurwitz, W. L "Notes on the history of intercultural communication: The Foreign Service Institute and the mandate for intercultural training." Quarterly Journal of Speech, 19"0, 76, pp.261281 .

[10] Byram, M., "Teaching and Assessing Intercultural Communicative Competence." Multilingual Matters.1997

[11] Byram, M., "From foreign language education to education for intercultural citizenship.” Intercultural Communication Review, 2011, 9 , pp.17-36.

[12] Schneckenberg, D., Ehlers, U., Adelsberger, H., "Web 2.0 and competence-oriented design of learning-potentials and implications for higher education." British Journal of Educational Technology 2011, 42 (5), pp.747-762.

[13] Brislin, R. W., \&Brandt, M. E. "Conceptualizations of Intercultural Behavior and Training. In D. Landis and R. W. Brislin (Eds.)," Handbook of Intercultural Training, 1983, (Vol. 1). New York: Pergamon. 